\title{
Benign esophagorespiratory fistula: A forgotten cause of chronic lung disease
}

TA HORAN, JD URSCHEL. Benign esophagorespiratory fistula: A forgotten cause of chronic lung disease. Can J Gastroenterol 1993;7(3):303-305. Benign acquired esophagorespiratory fistulas are an uncommon but eminently treatable cause of chronic lung disease. The diagnosis is easily made once it is considered as a possibility. Although medical and endoscopic treatment approaches are suitable in selected cases, surgical therapy is recommended for most patients.

Key Words: Esophageal diverticulum, Esophageal fistula, Tuberculosis

\section{Fistule oesophago-respiratoire bénigne : cause oubliée de} maladie pulmonaire chronique

RÉSUMÉ: Les fistules oesophago-respiratoires bénignes acquises sont une cause rare mais facilement traitable de maladie pulmonaire chronique. Bien que les approches thérapeutiques médicales et endoscopiques conviennent dans certains cas, l'approche chirurgicale demeure la plus recommandée chez la plupart des patients.

Department of Surgery, University of Manitoba, Winnipeg, Manitoba

Correspondence: Dr JD Urschel, 205, 8705 Meadowlark Road, Edmonton, Alberta T5R 5 W5

Received for publication July 25, 1992. Accepted November 23, 1992
Renign aCQuired ESOPHAGORESpiratory fistula is a rare cause of chronic lung disease. The diagnosis, although simply made, is often delayed because this condition is not normally considered initially. To increase awareness of this cause of chronic lung disease we report a case of esophagorespiratory fistula complicating an esophageal traction diverticulum where the diagnosis eluded physicians for 10 years.

\section{CASE PRESENTATION}

A 56-year-old woman presented with a 10-year history of intermittent cough, fever and hemoptysis. Recurrent episodes of right lower lobe pneumonia had been successfully treated with antibiotics. At the age of three she had been hospitalized for Pott's disease of the spine. Her father had died of 


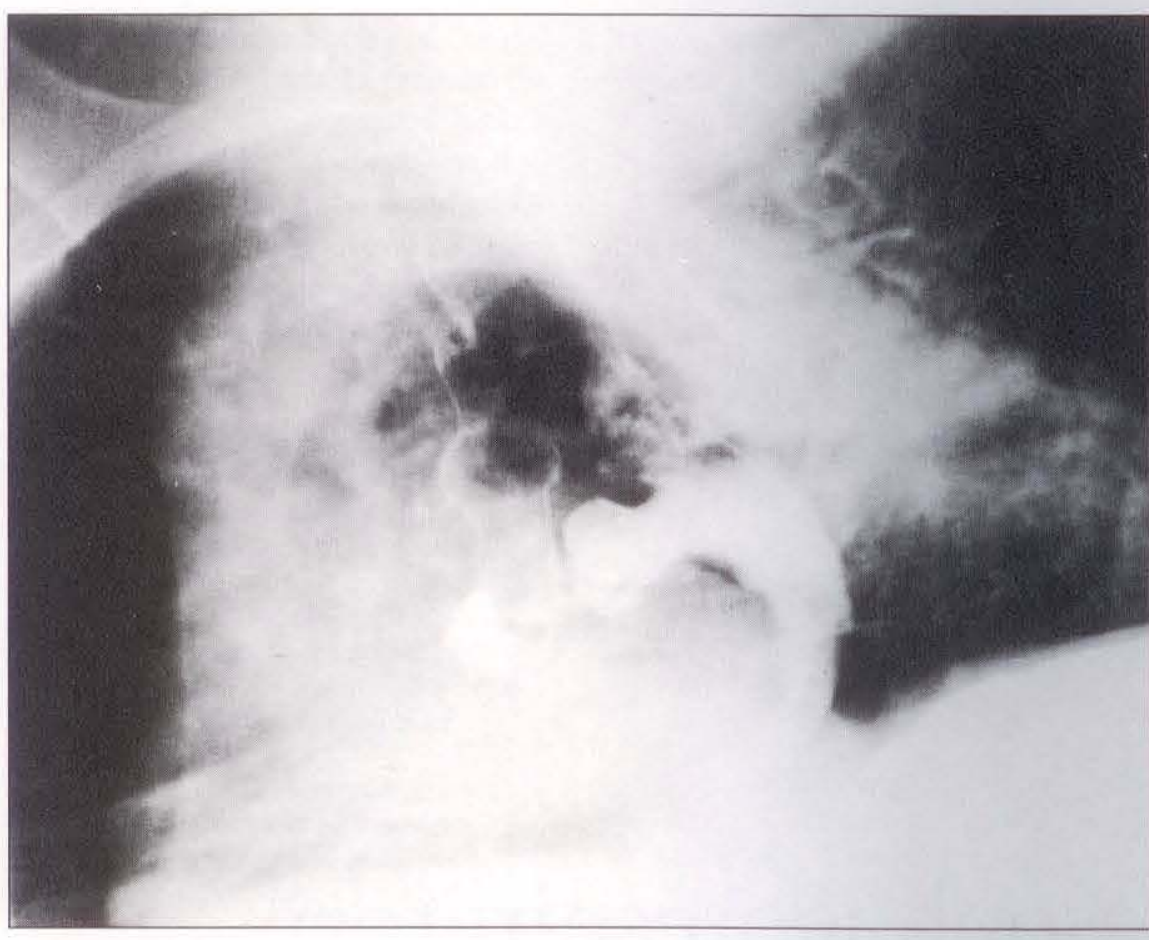

Figure 1) Esophagram demonstrating esophageal diverticulum and esophagobronchial fistula

tuberculosis. Dysphagia of recent onset prompted further investigation. A relationship between drinking liquids and coughing was not appreciated by the patient until diagnostic investigations were complete.

Sputum cultures were negative for mycobacterium and fungi. A barium swallow demonstrated a wide mouthed diverticulum in the subcarinal region with a fistula to the right bronchus intermedius (Figure 1). Flexible esophagoscopy confirmed the presence of a fistula and served to exclude a malignant etiology.

A right thoracotomy was performed. The diverticulum, fistula tract and adherent lymph nodes were excised. Esophageal and bronchial closures were buttressed with an interposed intercostal muscle pedicle. Microscopic examination of the diverticulum demonstrated squamous epithelium surrounded by smooth muscle. The findings were compatible with an esophageal diverticulum of traction etiology. No further episodes of pulmonary infection have occurred in two years of follow-up.

\section{DISCUSSION}

Benign acquired esophagorespiratory fistulas may result from traumatic injury, foreign bodies, endoscopic instrumentation, prolonged tracheal intubation, granulomatous infections, and esophageal traction diverticuli (1). Fistulas caused by trauma, instrumentation, or tracheal intubation are usually characterized by an acute and dramatic presentation that contrasts with the chronic and insidious nature of fistulas of inflammatory or diverticular etiology. Fistulas of inflammatory and diverticular origin, having clinical and pathophysiological similarities, will be discussed together.

In granulomatous diseases, fistulization occurs as a sequela of chronic mediastinal lymphadenitis. Traction diverticuli, being secondary to granulomatous lymphadenitis, may fistulize by an extension of the original mediastinal inflammatory process or by unrelated diverticular ulceration and perforation (2). While granulomatous infections and esophageal diverticuli were relatively common etiologies of esophagorespiratory fistulas in the past, the reduction in tuberculous infection in the developed world has reduced both the prevalence of the problem and the diagnostic awareness of physicians. A delay of several years in diagnosis is not unusual (2).
The diagnosis of an esophagorespiratory fistula is suggested by a history of coughing after drinking. If the fistula is small, the temporal relationship of coughing after drinking may not be appreciated by patient or physician. An esophagram usually demonstrates the fistula. Bronchographic contrast agents are preferable to barium. Esophagoscopy and bronchoscopy will confirm the presence of a fistula and serve to exclude malignancy. Should difficulty be encountered in demonstrating the communication, instillation of methylene blue into the esophagus during bronchoscopy is valuable (3).

Although surgical intervention was recommended for all benign esophagorespiratory fistulas at one time, medi$\mathrm{cal}$ and endoscopic treatment approaches have been successful in carefully selected patients. Management decisions are based upon the etiology and size of the fistula and the condition of the involved lung. Fistulas in the setting of active granulomatous infection may close with antituberculous or antifungal chemotherapy $(4,5)$. If active infection has long passed, which is often the case, antimicrobial therapy is of limited value. Small esophagorespiratory fistulas have been obliterated by endoscopic application of adhesive agents, but experience is limited $(6,7)$. If the fistula is large, or pulmonary resection for irreversibly diseased lung is required, surgical closure of the fistula is preferred.

Surgical management is favoured for most benign acquired esophagorespiratory fistulas. The principles of operative management include fistula division, esophageal and bronchial closure, interposition of local tissue between the two suture lines and concomitant resection of irreversibly diseased segments of lung. Fistula recurrence is unusual (8).

\section{REFERENCES}

1. Hilgenberg AD, Grillo HC. Acquired nonmalignant tracheoesophageal fistula. J Thorac Cardiovasc Surg 1983;85:492-8.

2. Stewart WRC, Klassen KP, Horava AP. Esophagobronchial fistula due to esophageal traction diverticulum. Arch Surg 1958;76:317-21.

3. Yacoub MH, You KD, Kittle CF. Non-malignant tracheobroncho- 
oesophageal fistula in an adult. $\mathrm{Br} J$ Dis Chest 1973;67:161-6.

4. Bashi SA, Laajam MB, Joharjy IA, Abdullah AK. Tuberculous oesophagopulmonary communication: Effectiveness of antituberculous chemotherapy. Digestion 1985;32:145-8.

5. Coss KC, Wheat LJ, Conces DJ, Brashear RE, Hull MT. Esophageal fistula complicating mediastinal histoplasmosis - response to amphotericin B. Am J Med 1987;83:343-6.

6. Barthelemy C, Audigier JC, Fraisse H. A non-tumoral esophago-bronchial fistula managed by isobutyl2-cyanoacrylate. Endoscopy 1983;15:357-8.
7. Marone G, Santora LM, Torre V. Successful endoscopic treatment of GL-tract fistulas with a fast-hardening amino acid solution. Endoscopy 1989;21:47-9.

8. Wychulis AR, Ellis FH, Anderson HA. Acquired nonmalignant esophagotracheobronchial fistula. JAMA 1966;196:103-8. 


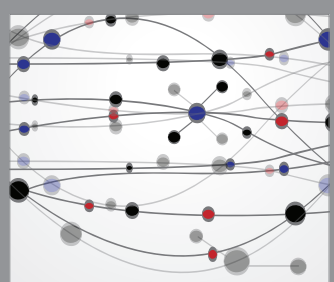

The Scientific World Journal
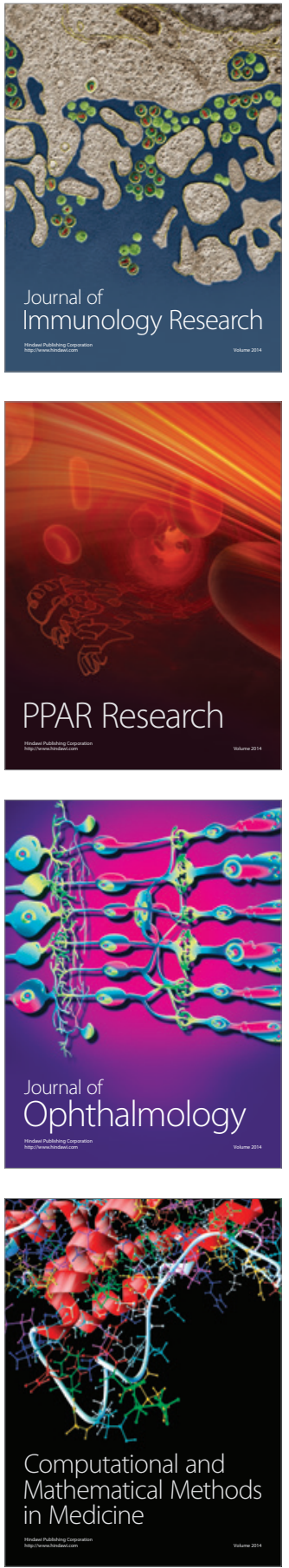

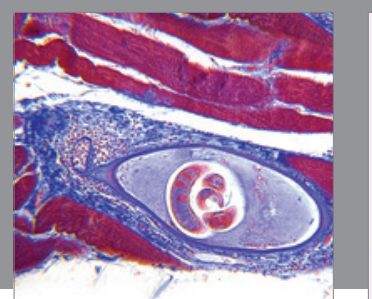

Gastroenterology Research and Practice

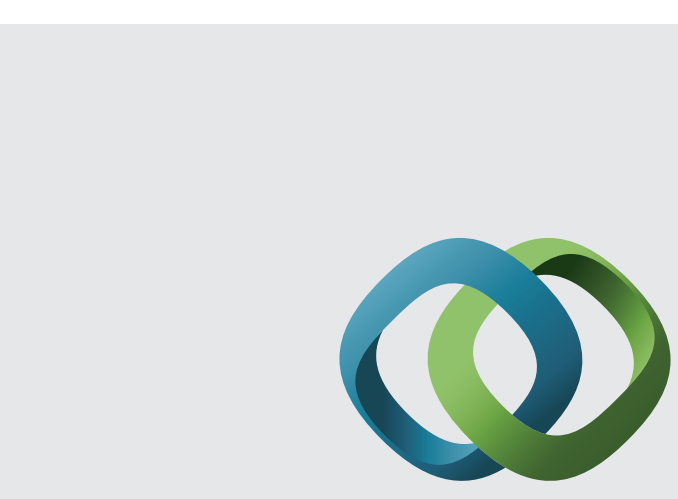

\section{Hindawi}

Submit your manuscripts at

http://www.hindawi.com
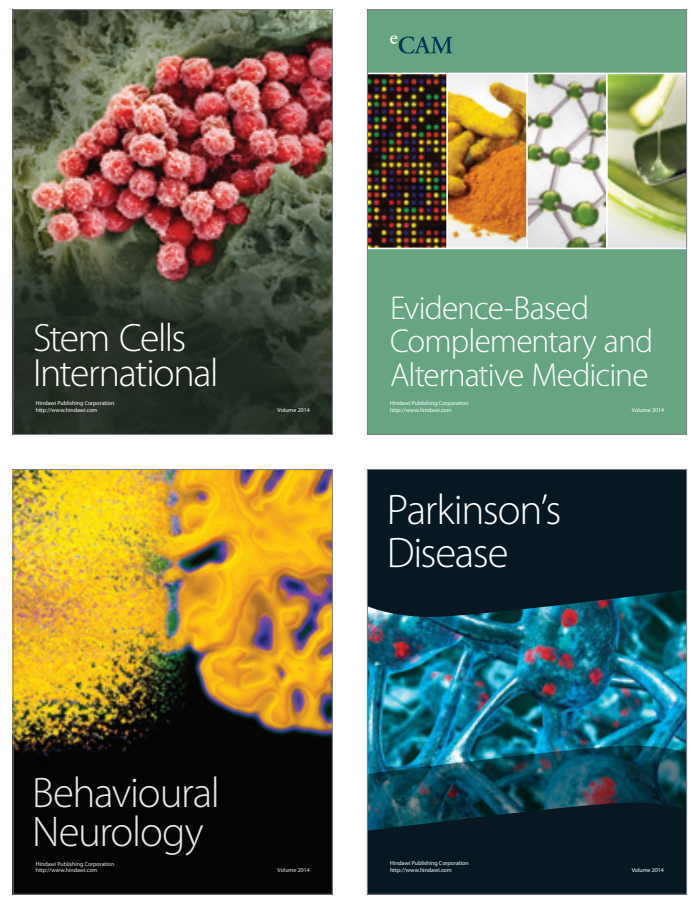
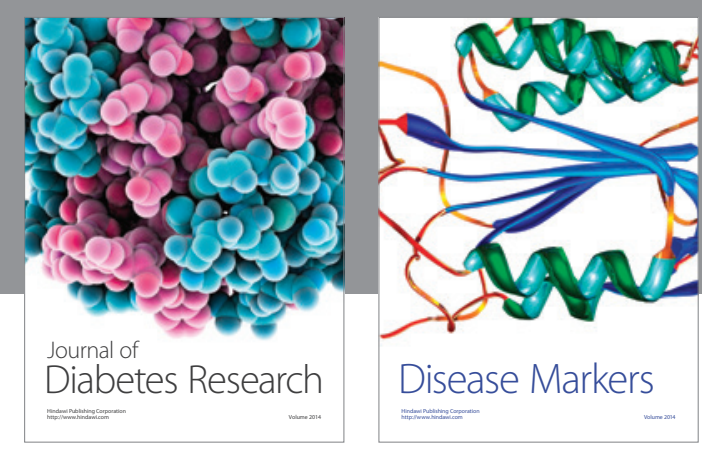

Disease Markers
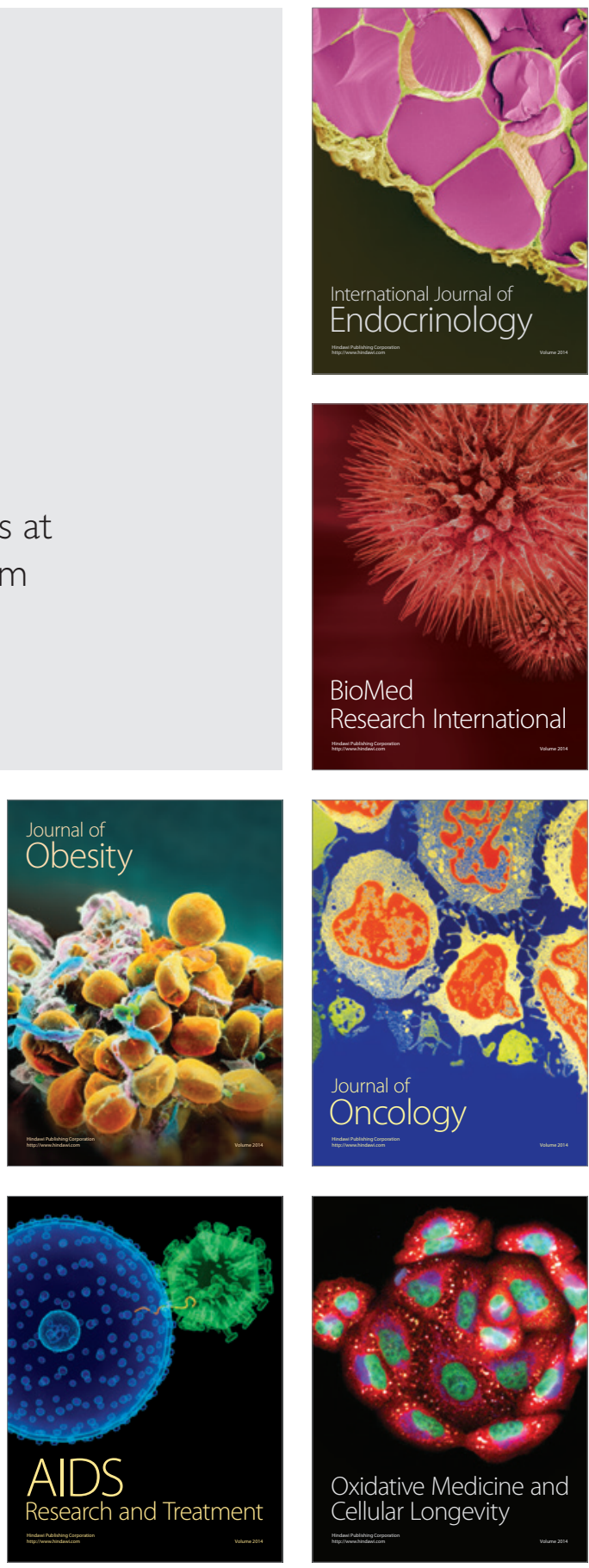